\title{
Effect of Endurance Training on Balance in Parkinson's Patients
}

\author{
NAWAL A. ABU SHADY, Ph.D.*; ALIAA H. MANSOUR, M.D.**; AHMED I.M. KHALEFA, M.Sc.* and \\ EMAN Y. SALEM, Ph.D.*** \\ The Department of Physical Therapy of Neuromuscular Disorders \& its Surgery, Faculty of Physical Therapy, Cairo University* \\ The Department of Neurology, Faculty of Medicine, Ain Shams University** and Fitness \& Rehabilitation Unit, \\ Faculty of Medicine, Cairo University***
}

\begin{abstract}
Background: Postural instability and resulting falls are major factors determining quality of life, morbidity, and mortality in individuals with Parkinson's Disease (PD).

Aim of Study: This study was to determine if there is an effect of endurance training on balance in idiopathic Parkinson's patients.

Patients and Methods: A referred diagnosed twenty Parkinson patients from both genders, with age ranged from (60$65)$ years old, were randomly assigned to equal two groups: A study group and a control group. Control group received conventional physical therapy program (Wobble board training, ROM, stretching exercises and gait training). For 12 sessions every other day, each session for one hour and study group received endurance training exercises in addition to conventional physical therapy program as control group, each session for one and half hours (one hour conventional treatment and 30 minutes treadmill training). All patients were evaluated with Biodex Stability System (BSS) including dynamic limit of stability test, dynamic balance test and functional reach test pre and post-treatment. The study was done in out clinics and balance lab. of Faculty of Physical Therapy, Cairo University for one month.
\end{abstract}

Results: This study revealed that there is a significant improvement in balance in both groups but there was no significant difference between both groups.

Conclusion: This study concluded that four weeks of endurance training combined with conventional physical therapy program for every patient was effective physical therapy technique on balance impairment in Parkinson's patients.

Key Words: Balance - Parkinson's disease - Endurance training.

\section{Introduction}

PARKINSON'S Disease (PD) is a common progressive neurological disorder in the aged popula-

Correspondence to: Dr. Nawal A. Abu Shady, The Department of Physical Therapy of Neuromuscular Disorders and its Surgery, Cairo University tion of Europe. A range of motor and non-motor symptoms have severe consequences for the functioning of the patient, affecting the everyday activities and Quality of Life [1]

Gait disturbances in PD are frequently associated with an increased risk of falls and cause loss of independence and a negative impact on the patients' quality of life. Therefore, improving gait ability is a primary goal of physical therapy in patients with PD [2].

Balance is a complex function involving numerous neuromuscular processes. Balance is controlled by sensory input, central processing, and neuromuscular responses. The sensory components include the vestibular, visual, and proprioceptive systems. An effective motor response requires an intact neuromuscular system and sufficient muscle strength to return the center of mass within the base of support when balance is disturbed [3].

Maintenance of stable posture depends on the efficient processing and integration of information from the visual, somatosensory, and vestibular systems and the modulation of efferent responses by the musculoskeletal system [4]. Falling is a frequent complication among the elderly. It not only causes medical and social impairments, such as fall-related injuries and loss of independence, also induces fear of falling which can result in a substantial decline in quality of life [5]

Postural instability and balance impairments are common symptoms of PD, contributing to an increased frequency of falls and injuries which in turn increases morbidity and mortality. The large impact of postural instability on patients is a significant concern, especially considering that dopamine replacement medications are often insufficient to control these deficits [6]. 
Endurance exercise training can be defined as an exercise that improves cardiorespiratory power and cardiorespiratory endurance Cardiorespiratory power is measured in terms of maximal oxygen uptake or $\mathrm{VO} 2$ max (the gold standard objective physiological measure of aerobic power determined during a cardiovascular endurance test). Cardiorespiratory endurance is a function of how long an individual can perform an activity using large muscle groups and is correlated with $\mathrm{VO} 2 \max$ [7].

\section{Material and Methods}

\section{Subjects:}

A referred twenty patients diagnosed with idiopathic Parkinson's disease from both genders (10 males and 10 females) were selected from the Neurology and Internal Medicine out clinics of Al-Demerdash Hospitals, Ain Shams University, Faculty of Physical Therapy, Cairo University and Kasr Al-Aini Hospitals, from August 2018 to May 2019.

\section{Inclusion criteria:}

1- The patients in the study suffering from mild to moderate stage of Parkinson disease [2.5-3 according to modified Hoehn and Yahr scale (HYS)].

2- The age was ranged from 60 to 65 years old from both genders.

3- All patients diagnosed and referred by the neurologist.

4- All patients have moderate risk of fall according to functional reach test.

5- The Body Mass Index (BMI) ranged from 20$30 \mathrm{Kg} / \mathrm{m}^{2}$.

6- All patients are medically stable.

7- All patients can follow commands.

8- Patients should be ambulant.

9- Signed a consent form before starting the program which included the purpose, natures and potential risks of the study which explained to all patients.

10-All patients with same life style and educational level.

11 - All patients without cognitive or psychiatric disorders.

12- All patients with the same medical treatment.
Exclusion criteria in patients with:

1- Other causes of Parkinsonism.

2- Sever Parkinson disabilities with stage ranged from (4:5) according to modified Hoehn and Yahr scale).

3- Patient with musculoskeletal deformity.

4- Patient with cardiovascular or respiratory diseases.

5- Obesity (BMI more than $30 \mathrm{Kg} / \mathrm{m}^{2}$ ).

6- Patients with other neurological disorder as spinal cord injury or stroke.

7- Patients with impairment of sensation.

8- Patients with visual or hearing disorders.

9- Patients with history of tumors.

10- Patients with arousal disorder.

11 - Patients with fractures of lower limbs.

12- Bed ridden patients and dependent.

- Design of the study:

Single investigator examined all patients to exclude inter investigator errors. Patients were divided into control group $(n=10)$ received conventional physical therapy program (Wobble board training, ROM exercises, stretching exercises and gait training), and a study group $(\mathrm{n}=10)$ received endurance training exercises (treadmill training) in addition to conventional physical therapy program. All patients in this study were assessed using Biodex Stability System (BSS) including dynamic limit of stability test, dynamic balance test and functional reach test.

\section{- Procedures:}

\section{Instrumentations:}

All patients underwent baseline assessment, BBS used to assess balance for all patients in the study, this machine consists of a multi axial standing platform which was adjusted to provide varying degrees of platform tilt or platform instability. BBS permits up to $20^{\circ}$ of support surface tilt; the patient is challenged to maintain their Center Of Gravity (COG) over their Base of Support (BOS) by trying to keep the platform level. The maximum angle a person's body can achieve from vertical without losing balance were assessed, BBS consists of (A) Display module. (B) Support handle. (C) Force platform. Measures of BSS were 1- Overall limit of stability, 2- Forward-backward limit of stability, 3- Right-left limit of stability 4- Over all stability index. 
- Limit of stability test (LOS): Challenges patients to move and control their COG within their BOS. During each test trial, patients must shift their weight to move the cursor from the center target to a blinking target and back as quickly and with as little deviation as possible. This test is a good indicator of dynamic control within a normalized sway envelope, thus a higher score is more desirable than a lower score [8].

- In dynamic balance test (DBT): Patients were instructed to maintain their center of pressure in the smallest concentric rings (balance zones) of the BBS monitor, named A zone. To begin, patients stood on the BBS's locked platform. To assess the foot position coordinates and establish the patient ideal foot positioning for testing, the stability platform was unlocked to allow motion. Testing began as the platform was released for a 20sec. trial and patients were asked to maintain an upright standing position on their lower limbs, for the trial to be complete, balance needed to be maintained for $20 \mathrm{sec}$.

- The Functional Reach Test (FRT) measures the maximum distance reached in a forward direction.it was shown that the (FRT) has a high predictive validity, test-retest reliability and inter observer reliability [9].

- After the examiner explained the FRT, each patient performed one practice trial and three test trials. FR was measured by using a tape measure attached to the wall at the height of the patient's acromion. To measure the patient's reaching distance, an examiner stood four feet away from the tape measure and recorded the initial and end reach positions. Patients stood comfortably with feet approximately shoulder-width apart, made a loose fist, and, without touching the wall, placed the arm parallel to the tape measure (initial position). Patients then reached as far forward as they could without losing their balance (end position). The position of the third metacarpal joint along the tape measure was recorded at both the initial and end positions. Patients were allowed to bal- ance on their toes; however, touching the wall, stepping while reaching forward, or holding onto their clothing with the other hand invalidated the trial. All patients were guarded during the test. The mean difference between the initial and end positions for the three test trials was calculated as the functional reach according to the following interpretations [10]:

- Very high risk: Unable to reach.

- High risk: Reach of less than 6" (15,2cm).

- Moderate risk: Reach of 6" to 10 " (15,2 to 25,4 $\mathrm{cm})$.

- Low risk: Reach greater than 10" $(25,4 \mathrm{~cm})$.

\section{Data analysis:}

The statistical analysis was conducted by using statistical SPSS Package program version 25 for Windows (SPSS, Inc., Chicago, IL). The statistical procedures were summarized as the following as shown in (Tables 1-7) and Figs. (1-8):

A- Descriptive statistics: Including the $\mathrm{X}$ and $\pm \mathrm{SD}$ for demographic data for all patients, Dynamic Balance Test (DBT) (stability index of static balance test), and Dynamic Limit Test (DLT) (stability index of dynamic limit test) variables.

B- Wilcoxon test: To compare between pre and post-treatment programs within each group for DBT and DLT variables.

C-Mann-Whitney U-test: To compare between both programs for demographic data, DBT and DLT variables.

D-Chi-square test $\chi^{2}$-test): To compare between pre and post-treatment within each group. Also, to compare between both programs for FRT variable.

E- Statistical level: All statistical analysis was significant at level of probability less than or equal $0.05(p \leq 0.05)$.

\section{Results}

A- Demographic data of all patients in this study:

Table (1): Comparison demographic data mean values between both programs.

\begin{tabular}{lllll}
\hline Items & Age (year) & Weight $(\mathrm{kg})$ & Height $(\mathrm{cm})$ & BMI $\left(\mathrm{kg} / \mathrm{m}^{2}\right)$ \\
\hline Conventional program & $62.30 \pm 2.11$ & $79.70 \pm 7.48$ & $169.40 \pm 9.64$ & $28.00 \pm 1.34$ \\
Endurance program & $63.00 \pm 1.70$ & $75.50 \pm 6.77$ & $165.30 \pm 8.00$ & $28.08 \pm 0.88$ \\
Z-value & 0.731 & 1.249 & 1.175 & 0.076 \\
$p$-value & 0.465 & 0.212 & 0.240 & 0.939 \\
Significance (S) & $\mathrm{NS}$ & $\mathrm{NS}$ & $\mathrm{NS}$ & $\mathrm{NS}$ \\
\hline SD : Standard Deviation. & & & \\
$p$-value : Probability value. & & & \\
NS : Non-Significant. & & & \\
Z-value & & &
\end{tabular}




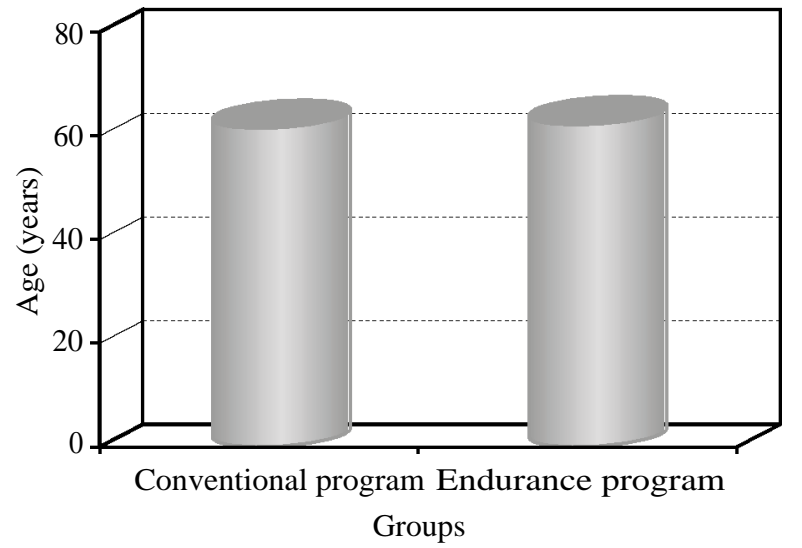

Fig. (1): Mean values of age in both programs.

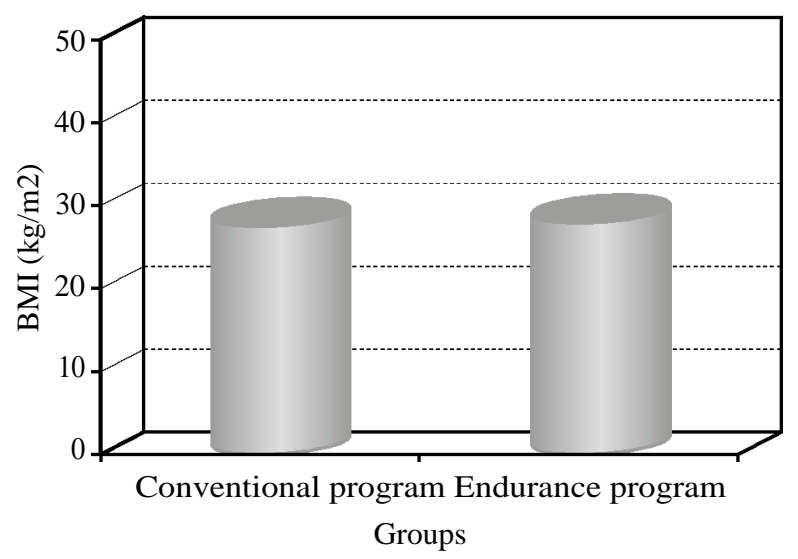

Fig. (2): Mean values of BMI of both programs.

Table (2) and Fig. (3) represented the comparative mean values between pre-and post-stability index of static balance test within each group. In conventional program, the mean values of pre-and post-stability index of static balance test were 3.56 \pm 1.25 and $3.32 \pm 1.35$, respectively, with improvement percentage $6.74 \%$. In endurance program, the mean values of pre-and post-stability index of static balance test were $4.38 \pm 1.02$ and $3.41 \pm 1.10$, respectively, with improvement percentage $22.15 \%$. The statistical analysis by Wilcoxon test revealed there were significantly decreased in stability index of static balance test at post-treatment compared to pre-treatment within conventional program group $(p=0.018 ; p<0.05)$ and endurance program group $(p=0.0001 ; p<0.05)$.

Table (3) and Fig. (4) represented the comparative mean values of pre-and post-stability index of static balance test between conventional program and endurance program. The mean values of pretreatment stability index of static balance test were $3.56 \pm 1.25$ in conventional program group and 4.38 \pm 1.02 in endurance program group. Whereas, the mean values of post-treatment stability index of static balance test were $3.32 \pm 1.35$ in conventional program group and $3.41 \pm 1.10$ in endurance program group. The statistical analysis by Mann-Whitney U-test revealed that there were no significant differences in stability index of static balance test of pre-treatment $(p=0.059 ; p>0.05)$ and posttreatment $(p=0.596 ; p>0.05)$ between conventional program and endurance program.

Table (4) and Fig. (5) represented the comparative mean values between pre-and post-stability index of dynamic limit test within each group. In conventional program, the mean values of pre-and post-stability index of dynamic limit test were 3 . $14.60 \pm 3.13$ and $16.90 \pm 5.04$, respectively, with improvement percentage $15.75 \%$. In endurance program, the mean values of pre-and post-stability index of dynamic limit test were $12.10 \pm 1.79$ and $17.60 \pm 3.71$, respectively, with improvement percentage $45.45 \%$. The statistical analysis by Wilcoxon test revealed there were significantly increased in stability index of dynamic limit test at post-treatment compared to pre-treatment within conventional program group $(p=0.005 ; p<0.05)$ and endurance program group $(p=0.0001 ; p<0.05)$.

Table (5) and Fig. (6) represented the comparative mean values of pre-and post-stability index of dynamic limit test between conventional program and endurance program. The mean values of pretreatment stability index of dynamic limit test were $14.60 \pm 3.13$ in conventional program group and $12.10 \pm 1.79$ in endurance program group. Whereas, the mean values of post-treatment stability index of dynamic limit test were $16.90 \pm 5.04$ in conventional program group and $17.60 \pm 3.71$ in endurance program group. The statistical analysis by MannWhitney-U test revealed that there were no significant differences in stability index of dynamic limit test of pre-treatment $(p=0.062 ; p>0.05)$ and posttreatment $(p=0.820 ; p>0.05)$ between conventional program and endurance program.

Table (6) and Fig. (7) represented the comparative distribution of pre-and post-functional reach test within each group. In conventional program, the distribution of pre-functional reach test were $0(0 \%), 7(70 \%), 2(20 \%)$, and $1(10 \%)$ for low, moderate, high, and very high functional reach test, respectively, $3(30 \%), 4(40 \%), 2(20 \%)$, and $1(10 \%)$, respectively, for post-treatment. In endurance program, the distribution of pre-functional reach test were $0(0 \%), 4(40 \%), 4(40 \%)$, and 2 $(20 \%)$ for low, moderate, high, and very high functional reach test, respectively, 2 (20\%), 5 $(50 \%), 3(30 \%)$, and $0(0 \%)$, respectively, for post- 
treatmęnt. The statistical analysis by Chi-square test $\left(\chi^{2}\right.$ test) revealed there were no significant differences in functional reach test of pre-treatment and post-treatment within conventional program group ( $p=0.280 ; p>0.05)$ and endurance program group $(p=0.235 ; p>0.05)$.

Table (7) and Fig. (8) represented the comparative distribution of pre-and post-functional reach test between conventional program and endurance program. In conventional program, the distribution of pre-functional reach test were $0(0 \%), 7(70 \%)$, $2(20 \%)$, and $1(10 \%)$ for low, moderate, high, and very high functional reach test, respectively, 0 $(0 \%), 4(40 \%), 4(40 \%)$, and $2(20 \%)$, respectively, in endurance program. In conventional program, the distribution of post-functional reach test were $3(30 \%), 4(40 \%), 2(20 \%)$, and $1(10 \%)$ for low, moderate, high, and very high functional reach test, respectively, 2 (20\%), 5 (50\%), 3 (30\%), and $0(0 \%)$, respectively, in endurance program. The statistical analysis by Chi-square test $\left(\chi^{2}\right.$ test) revealed there were no significant differences in functional reach test for pre-treatment and posttreatment between conventional program group $(p=0.403 ; p>0.05)$ and endurance program group $(p=0.680 ; p>0.05)$.

Table (2): Comparison mean values pre-and post-stability index of static balance test within each group.

\begin{tabular}{|c|c|c|}
\hline \multirow[b]{2}{*}{ Items } & \multicolumn{2}{|c|}{ Stability index of static balance test } \\
\hline & $\begin{array}{c}\text { Conventional } \\
\text { program }\end{array}$ & $\begin{array}{c}\text { Endurance } \\
\text { program }\end{array}$ \\
\hline Pre-treatment (mean $\pm \mathrm{SD})$ & $3.56 \pm 1.25$ & $4.38 \pm 1.02$ \\
\hline Post-treatment (mean $\pm \mathrm{SD})$ & $3.32 \pm 1.35$ & $3.41 \pm 1.10$ \\
\hline Mean difference & 0.24 & 0.97 \\
\hline Improvement $\%$ & $6.74 \%$ & $22.15 \%$ \\
\hline Z-value & 2.375 & 10.991 \\
\hline$p$-value $(p<0.05)$ & 0.018 & 0.0001 \\
\hline Significance & S & S \\
\hline $\begin{array}{ll}\text { SD } & : \text { Standard Deviation. } \\
\% & : \text { Percentage. }\end{array}$ & & \\
\hline $\begin{array}{l}p \text {-value : Probability. } \\
\mathrm{S} \quad \text { : Significant. }\end{array}$ & & \\
\hline
\end{tabular}

Table (3): Comparison mean values of pre-and post-stability index of static balance test between both groups.

\begin{tabular}{|c|c|c|}
\hline \multirow[b]{2}{*}{ Items } & \multicolumn{2}{|c|}{ Stability index of static balance test } \\
\hline & $\begin{array}{c}\text { Pre-treatment } \\
(\text { Mean } \pm \text { SD) }\end{array}$ & $\begin{array}{l}\text { Post-treatment } \\
\text { (Mean } \pm \text { SD) }\end{array}$ \\
\hline Conventional program & $3.56 \pm 1.25$ & $3.32 \pm 1.35$ \\
\hline Endurance program & $4.38 \pm 1.02$ & $3.41 \pm 1.10$ \\
\hline Mean difference & 0.82 & 0.09 \\
\hline Z-value & 1.890 & 0.530 \\
\hline$p$-value $(p<0.05)$ & 0.059 & 0.596 \\
\hline Significance & NS & NS \\
\hline
\end{tabular}

SD : Standard Deviation.

$p$-value : Probability.

NS : Non-Significant
Table (4): Comparison between mean values of pre-and poststability index of dynamic limit test within each group.

\begin{tabular}{lll}
\hline \multirow{2}{*}{ Items } & \multicolumn{2}{c}{ Stability index of dynamic limit test } \\
\cline { 2 - 3 } & $\begin{array}{c}\text { Conventional } \\
\text { program }\end{array}$ & $\begin{array}{c}\text { Endurance } \\
\text { program }\end{array}$ \\
\hline Pre_treatment (mean \pm SD) & $14.60 \pm 3.13$ & $12.10 \pm 1.79$ \\
Post-treatment (mean \pm SD) & $16.90 \pm 5.04$ & $17.60 \pm 3.71$ \\
Mean difference & 2.30 & 5.50 \\
Improvement \% & $15.75 \%$ & $45.45 \%$ \\
Z-value & 2.823 & 5.425 \\
$p$-value $(p<0.05)$ & 0.005 & 0.0001 \\
Significance & $\mathrm{S}$ & $\mathrm{S}$ \\
\hline SD : Standard Deviation. & $p$-value : Probability. \\
$\%$ : Percentage. & $\mathrm{S} \quad$ : Significant.
\end{tabular}

Table (5): Comparison mean values of pre-and post-stability index of dynamic limit test between both groups.

\begin{tabular}{|c|c|c|}
\hline \multirow{2}{*}{ Items } & \multicolumn{2}{|c|}{ Stability index of dynamic limit test } \\
\hline & $\begin{array}{c}\text { Pre-treatment } \\
(\text { Mean } \pm \text { SD) }\end{array}$ & $\begin{array}{l}\text { Post-treatment } \\
\text { (Mean } \pm \text { SD) }\end{array}$ \\
\hline Conventional program & $14.60 \pm 3.13$ & $16.90 \pm 5.04$ \\
\hline Endurance program & $12.10 \pm 1.79$ & $17.60 \pm 3.71$ \\
\hline Mean difference & 2.50 & 0.70 \\
\hline Z-value & 1.867 & 0.228 \\
\hline$p$-value $(p<0.05)$ & 0.062 & 0.820 \\
\hline Significance & NS & NS \\
\hline
\end{tabular}

SD : Standard Deviation. NS: Non-Significant.

$p$-value : Probability.

Table (6): Comparison between mean values of pre-and postfunctional reach test within each group.

\begin{tabular}{|c|c|c|c|c|}
\hline \multirow{3}{*}{ Items } & \multicolumn{4}{|c|}{ Functional reach test } \\
\hline & \multicolumn{2}{|c|}{$\begin{array}{l}\text { Conventional } \\
\text { program }\end{array}$} & \multicolumn{2}{|c|}{$\begin{array}{l}\text { Endurance } \\
\text { program }\end{array}$} \\
\hline & $\begin{array}{c}\text { Pre } \\
\text { treatment }\end{array}$ & $\begin{array}{l}\text { Post- } \\
\text { treatment }\end{array}$ & $\begin{array}{c}\text { Pre- } \\
\text { treatment }\end{array}$ & $\begin{array}{l}\text { Post- } \\
\text { treatment }\end{array}$ \\
\hline Low & $0(0 \%)$ & $3(30 \%)$ & $0(0 \%)$ & $2(20 \%)$ \\
\hline Moderate & $7(70 \%)$ & $4(40 \%)$ & $4(40 \%)$ & $5(50 \%)$ \\
\hline High & $2(20 \%)$ & $2(20 \%)$ & $4(40 \%)$ & $3(30 \%)$ \\
\hline Very high & $1(10 \%)$ & $1(10 \%)$ & $2(20 \%)$ & $0(0 \%)$ \\
\hline$\chi^{2}$-value & \multicolumn{2}{|c|}{3.818} & \multicolumn{2}{|c|}{4.254} \\
\hline$p$-value $(p<0.05)$ & \multicolumn{2}{|c|}{0.280} & \multicolumn{2}{|c|}{0.235} \\
\hline Significance & \multicolumn{2}{|c|}{ NS } & \multicolumn{2}{|c|}{ NS } \\
\hline
\end{tabular}

\begin{tabular}{lll}
\hline SD & Standard Deviation. & NS: Non-Significant. \\
$p$-value : & Probability.
\end{tabular}

Table (7): Comparison mean values of pre-and post-functional reach test between both groups.

\begin{tabular}{|c|c|c|c|c|}
\hline \multirow{3}{*}{ Items } & \multicolumn{4}{|c|}{ Functional reach test } \\
\hline & \multicolumn{2}{|c|}{ Pre-treatment } & \multicolumn{2}{|c|}{ Post-treatment } \\
\hline & $\begin{array}{l}\text { Conventional } \\
\text { program }\end{array}$ & $\begin{array}{c}\text { Endurance } \\
\text { program }\end{array}$ & $\begin{array}{c}\text { Conventional } \\
\text { program }\end{array}$ & $\begin{array}{c}\text { Endurance } \\
\text { program }\end{array}$ \\
\hline - Low & $0(0 \%)$ & $0(0 \%)$ & $3(30 \%)$ & $2(20 \%)$ \\
\hline - Moderate & $7(70 \%)$ & $4(40 \%)$ & $4(40 \%)$ & $5(50 \%)$ \\
\hline • High & $2(20 \%)$ & $4(40 \%)$ & $2(20 \%)$ & $3(30 \%)$ \\
\hline - Verry high & $1(10 \%)$ & $2(20 \%)$ & $1(10 \%)$ & $0(0 \%)$ \\
\hline - $\chi$-value & \multicolumn{2}{|c|}{1.817} & \multicolumn{2}{|c|}{1.511} \\
\hline $\begin{array}{c}\cdot p \text {-value } \\
(p<0.05)\end{array}$ & \multicolumn{2}{|c|}{0.403} & \multicolumn{2}{|c|}{0.680} \\
\hline - Significance & \multicolumn{2}{|l|}{ NS } & \multicolumn{2}{|l|}{ NS } \\
\hline
\end{tabular}




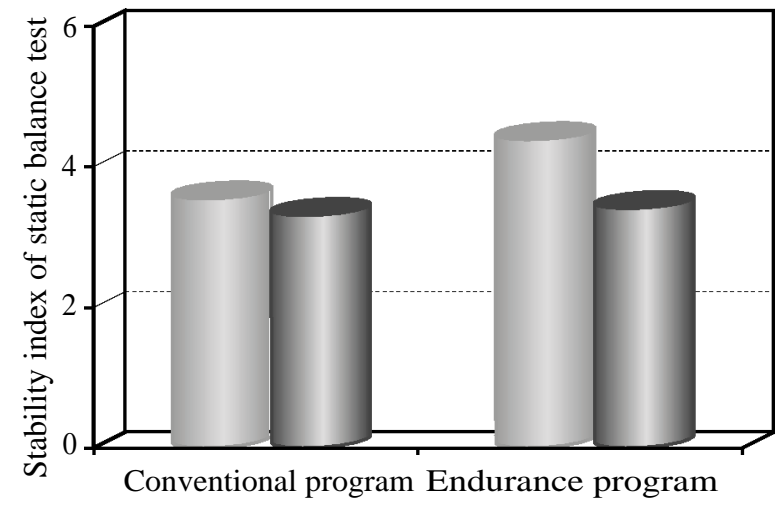

Groups

Pre-treatment | Post-treatment

Fig. (3): Mean values of pre-and post-stability index of static balance test within each group.

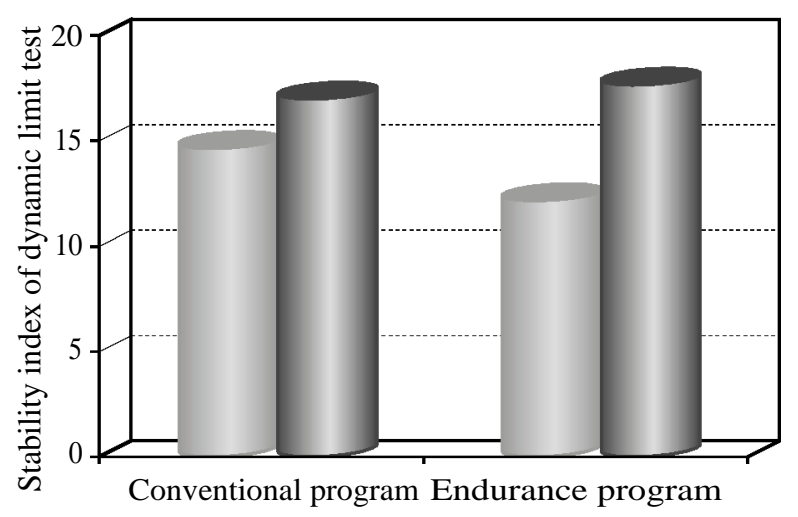

Groups

Pre-treatment | Post-treatment

Fig. (5): Mean values of pre-and post-stability index of dynamic limit test within each group.

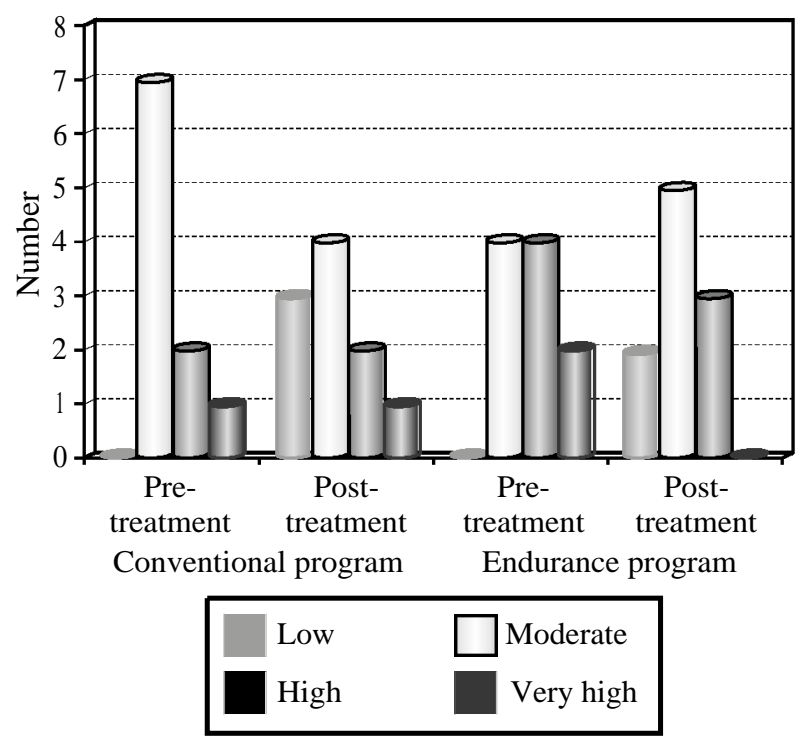

Fig. (7): Pre-and post-functional reach test within each group.

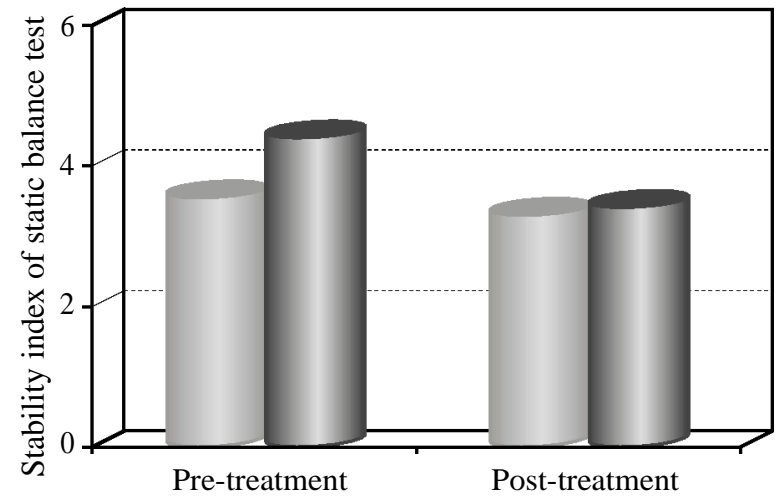

Treatments

Conventional program $\quad$ Endurance program

Fig. (4): Mean values of pre-and post-stability index of static balance test between both groups.

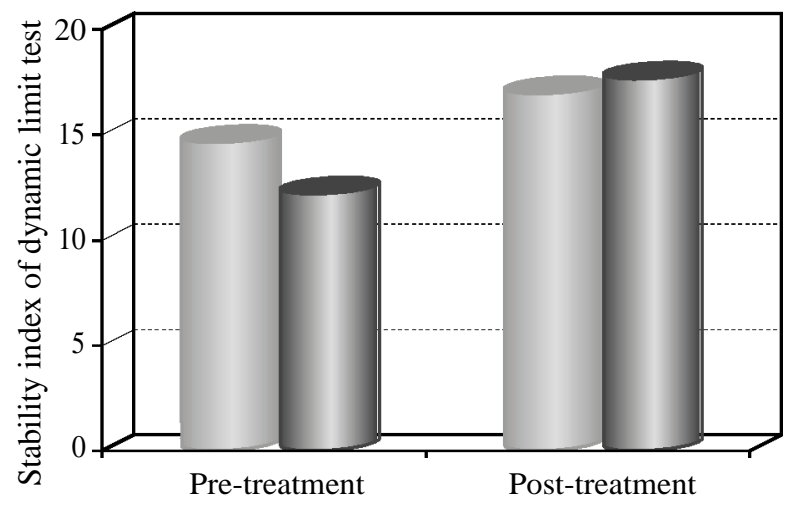

Treatments

Conventional program

Endurance program

Fig. (6): Mean values of pre-and post-stability index of dynamic limit test between both groups.

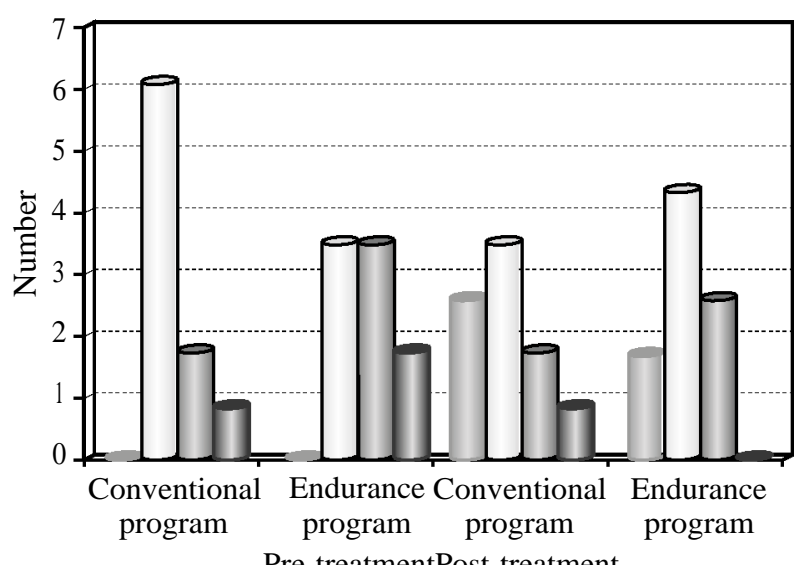

Pre-treatmentPost-treatment

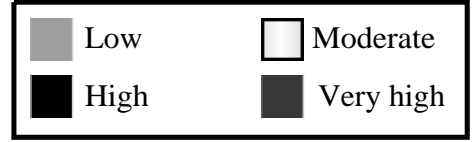

Fig. (8): Pre-and post-functional reach test between both groups. 


\section{Discussion}

The results of current study revealed that there was a significant decrease in the stability index of the static balance test post-treatment compared to pre-treatment within conventional program group and endurance program group, also there was a significant increase in stability index of the dynamic limit test post-treatment compared to pre-treatment within conventional program group and endurance program group but there was no significant difference between endurance training and conventional physical therapy treatment on balance in Parkinsonian patients. There were no significant differences in functional reach test for pre-treatment and posttreatment between conventional program group and endurance program group.

The results of the current study agreed with Sanjay S. et al., 2013 [11] who reported that specific modalities of exercise such as cardiovascular training, resistance training, and balance training are able to relieve patients debilitating motor and nonmotor symptoms and allow increasing functional ability to complete ADLs. The most beneficial exercise regimen likely combines these three modes of exercise to reduce both motor and non-motor symptoms.

The results of the current study agreed with Allen NE., et al., 2011 [12] who reported that reduced balance is associated with falls, poor mobility, disability and reduced quality of life in $\mathrm{PD}$ and balance is poorly responsive to levodopa. A recent meta-analysis concluded that exercise and motor training can improve the performance of balance-related activities in people with PD and recommended that highly challenging balance exercises be part of a rehabilitation program for patients with PD.

The data of the present study was supported by Lamotte G., et al., 2015 [13] who concluded that, there is not yet a proven effect of endurance exercise training on specific features of PD such as motor signs of Parkinsonism. There is insufficient evidence to include endurance exercise training as a specific treatment for PD. There is a need for well-designed large-scale randomized controlled trials to confirm benefits and safety of endurance exercise training in PD and to explore potential benefits on the motor and non-motor signs of PD.

Also according to Sage MD and Almeida QJ. 2009 [14] who reported that endurance exercise training alone is not sufficient to improve balance measures. This findings may be due to a lack of training specificity for balance in many endurance exercise interventions or the lack of sensitive balance testing.

The results of the present study disagreed with Margaret Schenkman, et al., 2008 [15] who reported that it is possible for people with mild or moderate PD to benefit from an endurance exercise program. Furthermore, the changes were not restricted to economy of movement, but extended to motor features of Parkinsonism, physical functional capacity, balance, and flexibility.

\section{Conclusion:}

It can be concluded that there was no significant effect of endurance training only on balance in Parkinsonian patients, but there was a significant effect of endurance training combined with the conventional therapy treatment on balance in the Parkinsonian patients so it should be considered a potential rehabilitation program.

\section{Ethical committee:}

No: P.T.REC/012/001938 (6/5/2018).

The research ethical committee accepts the plan of this research and the acceptance is valid from its date.

\section{References}

1- OLANOW C.W., STERN M.B. and SETHI K.: The scientific and clinical basis for the treatment of Parkinson disease. Neurology, 72 (21 Suppl 4): S1-136, 2009.

2- KEUS S.H.I., BLOEM B.R., HENDRIKS E.J.M., BREDERO-COHEN A.B. and MUNNEKE M.: Evidence-based analysis of physical therapy in Parkinson's disease with recommendations for practice and research. Mov. Disord, 22: 451-60, 2007.

3- JONES G., KANDEL E., SCHWARTZ J. and JESSEL T. POSTURE. In: (eds) Principles of neural science. McGraw-Hill, New York, pp. 816-31, 2000.

4- HORAK F.B.: Postural orientation and equilibrium: What do we need to know about neural control of balance to prevent falls? Age Ageing, 35 (suppl 2): ii7-ii11, 2006.

5- WHO, WHO global report on falls prevention in older age. Geneva, Switzerland: World Health Organization, 2007.

6- PAUL S. S., SHERRINGTON C., FUNG V.S. and CANNING C.G.: Neurorehabil Neural Repair. Motor and cognitive impairments in Parkinson disease: Relationships with specific balance and mobility tasks. Jan., 27 (1): 63 71, 2013.

7- VOSS M.W., VIVAR C., KRAMER A.F. and VAN PRAAG H.: Bridging animal and human models of exercise-induced brain plasticity. Trends Cogn. Sci. (Regul. Ed.), 17: 525-44, 2013.

8- CLARK S., ROSE D.J. and FUJIMOTO K.: Generalizability of the Limits of Stability Test in the Evaluation of 
Dynamic Balance Among Older Adults. Arch. Phys. Med. Rehabilitation, 78, 2008.

9- KATZ-LEURER M., I. FISHER, et al.: "Reliability and validity of the modified functional reach test at the subacute stage post-stroke." Disabil Rehabil, 31 (3): 243-8, 2010.

10- BEHRMAN A.L., LIGHT K.E., FLYNN S.M. and THIGPEN M.T.: Is the functional reach test useful for identifying falls risk among individuals with Parkinson's disease? Archives of Physical Medicine and Rehabilitation, 83 (4): 538-42. doi: 10.1053/apmr, 2002.

11- SANJAY SALGADO, NORI WILLIAMS, RIMA KOTIAN, and MIRAN SALGADO: An Evidence-Based Exercise Regimen for Patients with Mild to Moderate Parkinson's Disease. Brain Sci., 3 (1): 87-100, 2013

12-ALLEN N.E., SHERRINGTON C., PAUL S.S. and CANNING C.G.: Balance and falls in Parkinson's disease: A meta-analysis of the effect of exercise and motor training. Mov. Disord., 26: 1605-15, 2011.

13- LAMOTTE G., RAFFERTY M.R., PRODOEHL J., KOHRT W.M., COMELLA C.L., SIMUNI T. and CORCOS D.M.: Effects of Endurance Exercise Training on The Motor and Non-Motor Features of Parkinson's Disease: A Review. Journal of Parkinson's Disease, 5 (3): 621 621. doi:10.3233/jpd-159001, 2015.

14- SAGE M.D. and ALMEIDA Q.J.: Symptom and gait changes after sensory attention focused exercise vs aerobic training in Parkinson's disease. Mov. Disord., 24: 11328,2009 .

15- MARGARET SCHENKMAN, DEBORAH HALL, RAJEEV KUMAR and WENDY M. KOHRT: Endurance Exercise Training to Improve Economy of Movement of People With Parkinson Disease: Three Case Reports Physical Therapy, Volume 88, Issue 1, Pages 63-76, 2008.

\section{تآثير التدريب بقوة التحمل على الإتزان فى مرضى الشلل الرعاش}

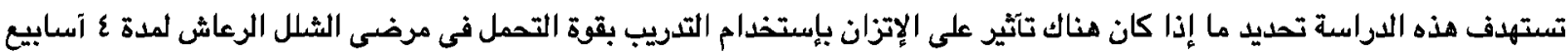

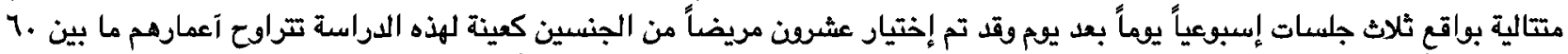

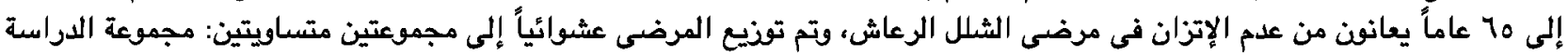

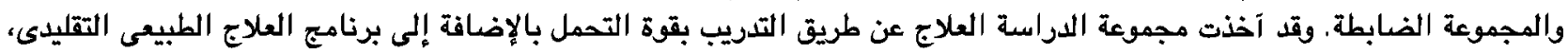

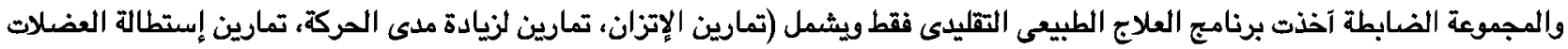

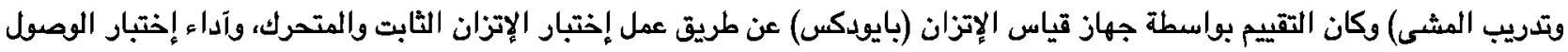

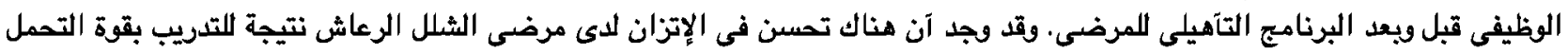

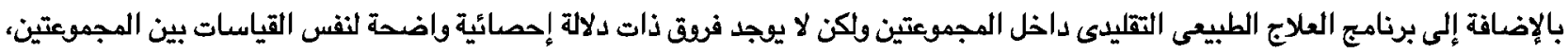
لذا ئخخ في الإعتبار تنظيم برنامج العلاج الطبيعى لمرضى الشلاعل الرعاش لعلاج المضاعفات مثل السقوط على الآرض المتكرر. 